\section{$\underset{\substack{\text { hommes } \\ \text { \& migrations }}}{ }$}

\section{Hommes \& migrations}

Revue française de référence sur les dynamiques

migratoires

1316 | 2017

L'islam en Europe

\title{
Sacrées graines
}

\section{Edith Canestrier}

\section{(2) OpenEdition \\ Journals}

\section{Édition électronique}

URL : http://journals.openedition.org/hommesmigrations/3818

DOI : 10.4000/hommesmigrations.3818

ISSN : 2262-3353

\section{Éditeur}

Musée national de l'histoire de l'immigration

\section{Édition imprimée}

Date de publication : 1 mars 2017

Pagination : 148-149

ISBN : 978-2-919040-37-7

ISSN : $1142-852 X$

\section{Référence électronique}

Edith Canestrier, «Sacrées graines », Hommes \& migrations [En ligne], 1316 | 2017, mis en ligne le 01 mars 2017, consulté le 18 septembre 2020. URL : http://journals.openedition.org/hommesmigrations/ 3818 ; DOI : https://doi.org/10.4000/hommesmigrations.3818 


\section{SACRÉES GRAINES}

Par ÉDITH CANESTRIER

"La graine ", c'est ainsi qu'on nomme communément le couscous. Plat traditionnel dans les cultures arabo-musulmanes, roboratif et convivial. L'un des mets préférés des Français. Et l'occasion, pour les treize artistes invités par l'Institut des cultures d'islam (ICI), de prendre des chemins de traverse. Sculpteurs, dessinateurs, performeurs, photographes, vidéastes s'emploient à examiner " la graine " sous l'angle de la spiritualité, de la transmission, de l'exil, de l'espace séparé entre hommes et femmes, entre citoyens d'un même pays, y compris, bien sûr, le nôtre.
Yazid Oulab, Algérien et Marseillais d'adoption, déploie à travers le dessin, la sculpture, la vidéo toute son inspiration, entre méditation soufie et loi du hasard. Même démarche méditative avec Mehdi-Georges Lahlou à travers une monumentale installation faite de fine semoule. Ici, c'est le temps qui passe, fragilise et effiloche les œuvres. En parcourant l'exposition, on y trouve les métaphores de tous les chaos du monde. Les deux valises de Naz Shahrokh sont un rappel des voyages anciens sur la route de la soie, impossibles aujourd'hui, qu'on soit victime de la guerre, de la 
répression ou de la misère.

Circulation symbolique avec Jean-Luc Moulène. Le photographe égrène tous les produits nécessaires à la confection du couscous. Cette semoule, cette huile d'olive, ces concentrés de tomate sont fabriqués en Palestine et n'en sortent pas, pas plus que leurs producteurs. Séparation, stigmatisation, violence. Les tamis qui forment la rosace de Mircea Cantor sont troués de balles.

Un même mot en arabe et en hébreu pour dire ma maison (Beiti). Laurent Mareschal, reproduit à même le sol le plan d'un appartement en trompe-l'œil constitué d'épices. Beiti, un mot commun en Israël et en Palestine, oui, mais... Séparer le bon grain de l'ivraie, voilà ce à quoi s'emploie la performeuse Ninar Esber. Trier une tonne de maïs formée de graines de trois couleurs différentes. Trier donc et... éliminer la mauvaise graine. On se sépare encore dans l'univers de l'artiste marocain Younès Rahmoun. Les hommes d'un côté, les femmes de l'autre. Et dans celui d'Abdelkrim Tajiouti qui, lui, est né en France, ce sont les citoyens qu'on sépare. Sa sculpture ? Un pied de nez à la devise républicaine : Liberté-Égalité-Kebab.

Quand ce n'est pas délibéré, c'est le regard qui fixe la séparation. Autoportrait de l'artiste Zoulikha Bouabdellah en triptyque, le couscoussier brandi. Algérienne, femme, musulmane.

" Ni, ni, ni » est le titre de son œuvre. Et la question qui va avec: "Et si je n'étais pas, ou pas seulement, celle que vous croyez?"

La bonne graine. @ D.R.

Des images du photographe anglais Martin Parr bouclent l'exposition. En résidence d'artiste à I'ICl en 2011, il a posé un regard tendre sur un quartier de Paris tant décrié. Ses photos sont une invitation à marcher sur ses pas, et donc à partager un couscous à La Table ouverte, le resto associatif niché au cœur de l'ICI. Pour l'artiste qui a titré ainsi ses photos, c'est cela aussi : "The Goutte d'Or »! !

\section{Institut des cultures d'islam 56 , rue Stephenson et 19 , rue Léon, Paris $18^{\mathrm{e}}$. Tél : 0153099984 www.ici.paris.fr}

